\title{
A Pulse Heating Method for the Measurement of Melting Point of Electrical Conductors (Thin Wires) Above $2000 \mathrm{~K}^{*}$
}

\author{
A. Cezairliyan
}

Institute for Materials Research, National Bureau of Standards, Washington, D.C. 20234

(June 30, 1970)

\begin{abstract}
A pulse heating method is described for the measurement of melting point of electrical conductors at high temperatures (above $2000 \mathrm{~K}$ ) which are in the form of thin wires. The technique is checked by measuring the melting point of platinum. The results give $2044 \pm 5 \mathrm{~K}$ on IPTS-1968.
\end{abstract}

Key words: High-speed measurements; high temperatures; melting point; platinum.

In general, melting points of substances are determided using quasi steady-state techniques, where the specimen is either heated or cooled very slowly until a phase change is detected. These methods present difficulties at high temperatures (above $2000 \mathrm{~K}$ ) due to increased heat transfer, chemical reactions, evaporation, loss of mechanical strength, etc.

In order to overcome most of these difficulties experiments may be performed in short times by heating the specimen rapidly to its melting point. A technique utilizing this approach was described in the literature [1]. ${ }^{1}$ The specimen was of tubular form $(100 \mathrm{~mm}$ long, $6.4 \mathrm{~mm}$ outside diameter, $0.5 \mathrm{~mm}$ wall thickness) with a small hole in the wall at the middle of the specimen. The cylindrical specimen approximated blackbody conditions for optical (pyrometric) temperature measurements. The specimen was heated from room temperature to its melting point in less than one second by the passage of a high current (2000 A) through it. The maximum temperature attained was the melting point. The melting point obtained by this method was reproducible within $1 \mathrm{~K}$ (standard deviation of the mean). The tubular specimen had to be destroyed during each determination. The cost and difficulty of fabricating specimens used in the above study make it unsuitable for general use.

The objective of this note is to describe a highspeed method of measuring melting point of electrical conductors (with melting points above $2000 \mathrm{~K}$ ) where the specimens are in the form of thin wires. The method is based on detecting melting of a specimen which is wound around a tube as the latter is heated rapidly in vacuum. The limitation of the measurements to temperatures above approximately $2000 \mathrm{~K}$ is im-

*This work was supported in part by the Propulsion Division of the U.S. Air Force Office of Scientific Research under contract ISSA-69-0001.

${ }^{1}$ Figures in brackets indicate the literature references at the end of this paper. posed by the optimization in the operation of the highspeed pyrometer.

The basic circuitry of the measurement system, shown in figure 1, was similar to that described in the literature [2]. The specimen was a high-purity $(99.999$ percent) platinum wire (diameter $=0.001 \mathrm{in}, 0.025 \mathrm{~mm}$ ),

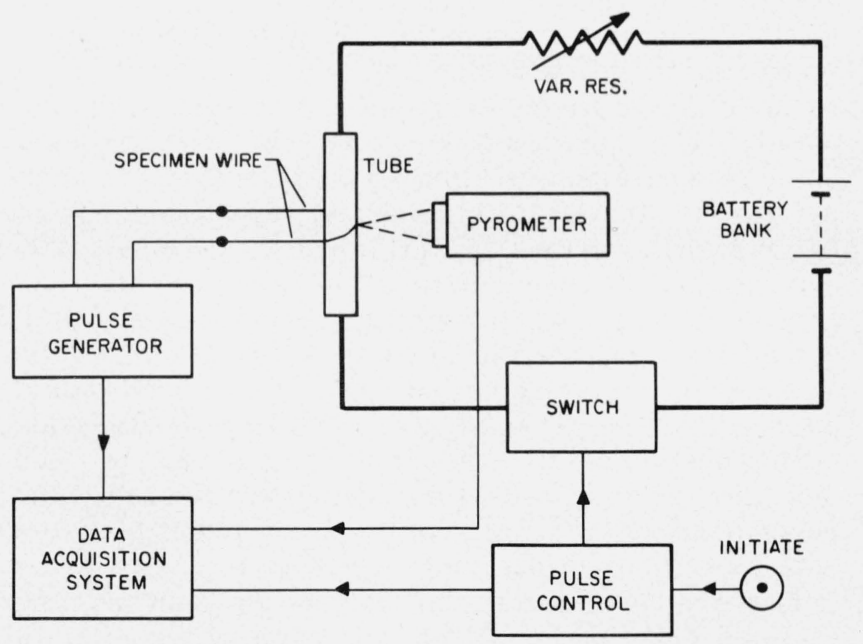

FigURE 1. Functional diagram of a high-speed system for the measurement of melting point of electrical conductors in the form of thin wires at high temperatures.

which was wound (half turn) around a thin-wall molybdenum tube. The tube was electrically in series with the main power pulsing circuit. Two pulleys supported the wire. A $0.5 \mathrm{~g}$ weight was attached to each end of the wire to assure good contact between the wire and the tube. A schematic drawing showing the specimen and the tube assembly is presented in figure 2. The ends of the platinum wire were connected to a special electronic circuit which indicated the time of the open- 
ing of the circuit resulting from the melting of platinum.

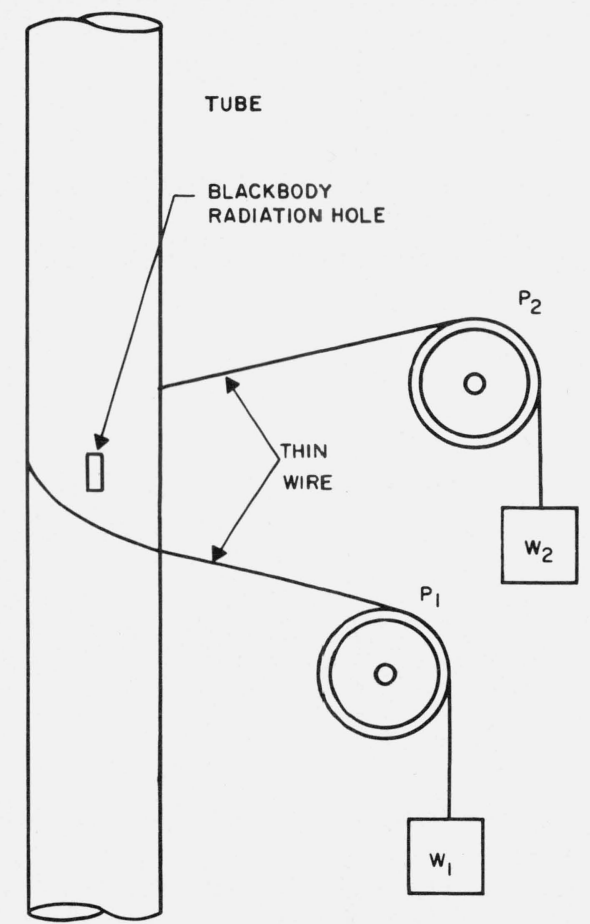

Figure 2. Schematic diagram of the specimen and tube assembly.

The break in the circuit took place at a point of contact with the tube as the latter was pulse heated. Duration of an experiment (heating of the specimen from room temperature to its melting point) was approximately $0.8 \mathrm{~s}$. Heating rate of the tube at the melting point of platinum was approximately $2 \mathrm{~K} \mathrm{~ms}^{-1}$. Temperature of the tube was measured with a high-speed photoelectric pyrometer [3], which permits 1200 evaluations of tube temperature per second. The pyrometer target was a small rectangular hole $(1 \mathrm{~mm}$ $\times 0.5 \mathrm{~mm}$ ) fabricated in the wall at the middle of the tube. Signals were recorded with a high-speed digital data acquisition system [2] which has a full-scale signal resolution of approximately one part in 8000 and time resolution of $0.4 \mathrm{~ms}$. Temperature of the tube corresponding to the time of the break in the platinum wire gave the melting point of platinum.

The results of three experiments gave an average value of $2044.2 \mathrm{~K}$ for the melting point of platinum on the 1968 International Practical Temperature Scale [4] with an average deviation from the mean of the three amounting to $1.1 \mathrm{~K}$. This compares favorably with the accepted value of $2045 \mathrm{~K}$ [4].

In each experiment, the contribution to the uncertainty in temperature resulting from the uncertainty in the "temperature-time of break" determination was $0.4 \mathrm{~K}$. The standard deviation of individual temperature measurements in each experiment was less than $0.3 \mathrm{~K}$. Correction due to the radial temperature gradient in the tube was less than $0.1 \mathrm{~K}$. Maximum inaccuracy in temperature measurements at the melting point of platinum, which results from uncertainties in standard lamp, pyrometer calibration, blackbody quality, scattered light, etc., is estimated to be $4 \mathrm{~K}$ [2]. Error in the melting point due to alloying effect is negligible since the entire experiment was of very short duration.

Because of the complex nature of the experimental method, it was difficult to determine exactly (1) the time constant for heat transfer between the tube and the specimen, and (2) the effect of the tension due to end weights on the melting point. Crude estimates indicated that this time constant could be of the order of $0.1 \mathrm{~ms}$, which corresponds to an error of the order of $0.2 \mathrm{~K}$ in the melting point. It is likely that in the experiments the lowering of the melting point due to tension in the specimen was approximately compensated by an opposite effect which resulted from the finite time constant associated with heat transfer between the tube and the specimen. One may conclude that the melting point of platinum, as determined in this study, is 2044 $\pm 5 \mathrm{~K}$ on IPTS -68 .

The results of preliminary work presented in this note have demonstrated the feasibility of measuring the melting point of electrical conductors in the form of thin wires by a pulse heating method of subsecond duration.

\section{References}

[1] Cezairliyan, A., Morse, M. S., and Beckett, C. W., Measurement of melting point and electrical resistivity (above $2840 \mathrm{~K}$ ) of molybdenum by a pulse heating method (to be published in Rev. Int. Hautes Tempér. et Réfract., 1970).

[2] Cezairliyan, A., Morse, M. S., Berman, H. A., and Beckett, C. W., J. Res. Nat. Bur. Stand. (U.S.), 74A (Phys. and Chem.), 65 (1970).

[3] Foley, G. M., High-speed optical pyrometer, Rev. Sci. Instr., 41, 827 (1970).

[4] International Practical Temperature Scale of 1968, Metrologia, 5, 35 (1969).

(Paper No. 74C3\&4-301) 